\title{
Nodules on the glans penis, an unusual metastatic pattern of prostate carcinoma: case report
}

\author{
G M van den BERG,* H E MENKE,* AND E STOLZ $\dagger$ \\ From the Departments of Dermatovenereology, * Sint Franciscus Gasthuis, Rotterdam, and †University Hospital \\ Rotterdam-Dijkzigt, Rotterdam, the Netherlands
}

SUMMARY A man aged 77 presented with nodules on the glans penis. Histological examination confirmed the diagnosis of metastases of prostatic carcinoma.

\section{Introduction}

Nodular lesions on the glans penis are often encountered in dermatovenereological practice. In most cases these lesions are inflammatory in origin, and sometimes their cause is infectious (such as syphilitic) or unknown (such as lichen planus). We present here a rare cause of nodules on the glans penis.

\section{Case report}

The patient, a man aged 77 , was referred to the department of dermatovenereology of St Franciscus Gasthuis on 4 September 1984 by his urologist because of a small painless nodule on the glans penis. He had never been treated for a sexually transmitted disease, and denied having had extramarital sexual contact. $\mathrm{He}$ had recently been admitted to the urological department because of pyocystitis caused by hypotonic bladder dysfunction resulting in urinary retention.

In 1975 he had undergone a transurethral prostatectomy for benign prostatic hypertrophy. A lobectomy of the right lung for a poorly differentiated bronchial carcinoma had been performed in 1977. In May 1984 the transurethral prostatectomy had been repeated, and well differentiated adenocarcinoma of the prostate gland was diagnosed.

On examination on 4 September 1984 he had a reddish non-ulcerating nodule $3 \mathrm{~mm}$ in diameter on the glans penis near the corona. No urethral discharge or inguinal lymphadenopathy existed. Serological tests for syphilis (Venereal Disease Research

Address for reprints: Mrs G M van den Berg, Department of Dermatovenereology, Sint Franciscus Gasthuis, Kleiweg 500, 3045 PM Rotterdam, the Netherlands

Accepted for publication 13 August 1985
Laboratory (VDRL) test and Treponema pallidum haemagglutination assay (TPHA)) and urethral culture for Neisseria gonorrhoeae gave negative results. An ointment containing sulphur was prescribed, but after two weeks the lesion had enlarged to $5 \mathrm{~mm}$ in diameter. A punch biopsy was taken on 27 September 1984. Though the histological pattern was suggestive of metastatic carcinoma of the prostate, no definite diagnosis could be made by the pathologist. A second specimen was therefore taken on 26 November 1984, this time by means of excision biopsy. Histological examination (figs 1 and 2) showed irregular glandular structures of pale cylindrical epithelial cells, with hyperchromatic nuclei that contained a central nucleolus. Papillary structures protruded into the acinar lumina. There was extensive invasion of the overlying epithelium and vascular spaces of the corpus spongiosum. The immunoperoxidase antibody stain for prostatic acid phosphatase was positive, which was consistent with the diagnosis of metastatic adenocarcinoma of the prostate.

Meanwhile multiple firm pinkish-red nodules (ranging from 4 to $8 \mathrm{~mm}$ in diameter) had developed on the glans penis near the corona (fig 3). In September 1984 hormonal treatment with diethylstilboestrol was started, but was stopped in December because of side effects. Bilateral orchidectomy was then performed, despite which more nodules appeared. In February 1985 severe pain and urinary obstruction developed. The patient subsequently agreed to partial amputation of the penis. Until March 1985 results of laboratory investigations including full blood count, plasma enzyme tests of liver function, concentrations of serum creatinine, urea-nitrogen, and calcium, and activity of alkaline phosphatase and prostate acid phosphatase had been normal. Radiographs and scintiscans disclosed no metastatic disease in lungs, liver, or bones. 


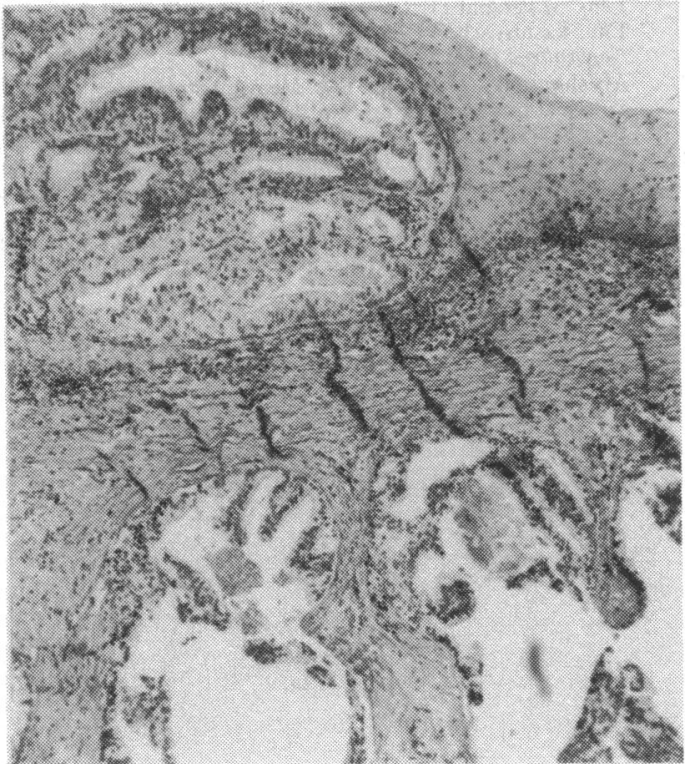

FIG 1 Section of biopsy specimen from nodule of glans penis showing irregular glandular structures invading the overlying epithelium (haematoxylin and eosin $40 \times$ original magnification).

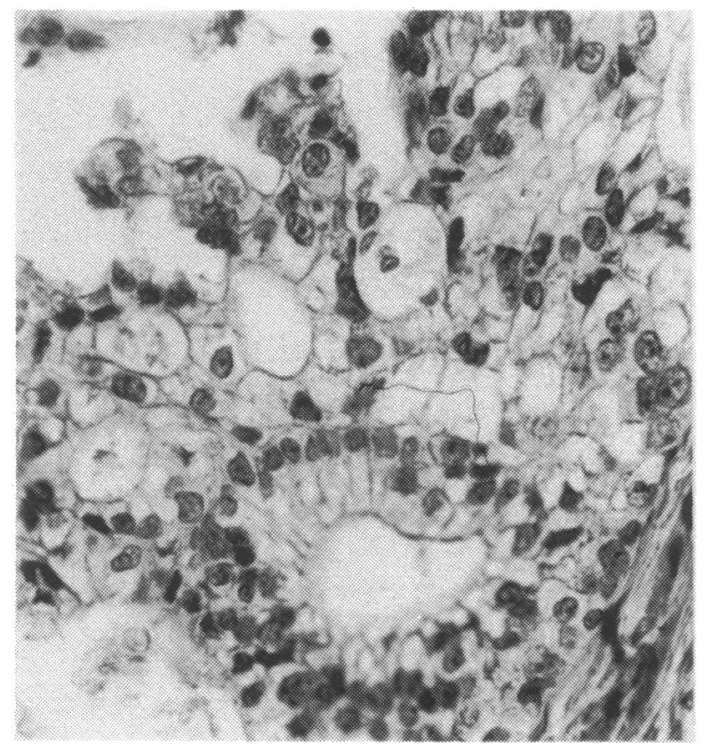

FIG 2 Detail of glandular structure showing irregular pale cylindrical epithelial cells with prominent nuclei and nucleoli (haematoxylin and eosin $100 \times$ original magnification).

\section{Discussion}

Penile metastases from prostatic carcinoma are rare. McCrea and Karafin studied 500 cases of prostatic carcinoma and reported only one case of metastasis to the penis. ${ }^{1}$ Among the 365 patients with prostatic carcinoma studied by Lenk and Patzold only one case of metastasis was noted. ${ }^{2}$ Reviews of reports published up to $1975^{3}{ }^{4}$ gave details of 170 cases of metastatic carcinoma of the penis. The primary cancer in most of these cases was in the bladder, rectum, kidney, or testis, apart from the prostate gland. The most common sign of metastasis to the penis, according to Abeshouse and Abeshouse, is a penile mass or a diffuse swelling. There may be priapism or pain. ${ }^{3}$

The possible mechanisms of dissemination of prostatic carcinoma to the penis are direct invasive growth, retrograde venous transportation, lymphatic transport, arterial embolisation, or implantation by instruments. The most comon routes are probably the direct invasive growth and the retrograde venous pathway. ${ }^{3}$ The prognosis of penile metastases is, regardless of their origin, usually very poor. As a rule widespread disease is present by the time of their appearance. Therapeutic possibilities are limited and usually consist of palliative measures for pain or priapism. The role of chemotherapy remains to be evaluated.

We present our case because metastasis to the penis is a rare phenomenon. The patient was exceptional because at the time of diagnosis there were no signs of metastases elsewhere or of an advanced primary tumour. Persistent penile nodules should raise suspicion about the existence of malignancy, especially when there is a history of carcinoma of the prostate, bladder, rectum, kidney, or testis. In such a case histological examination performed with special histochemical stains ${ }^{5}$ is necessary in order to make a definitive diagnosis.

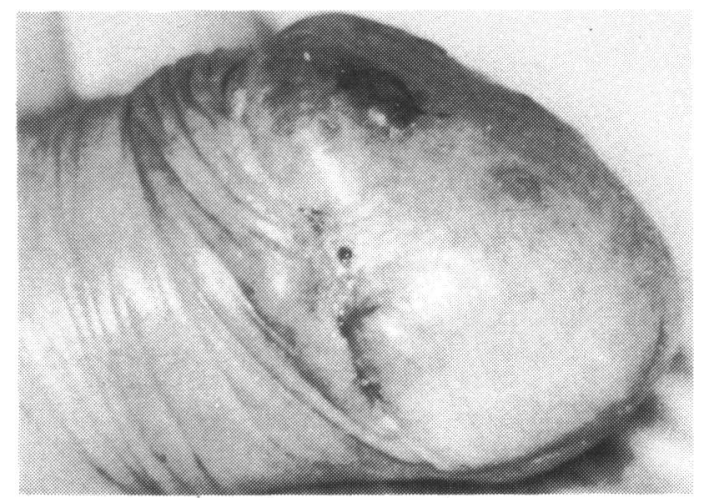

FIG 3 Glans penis showing multiple nodules near the corona glandis. 
We thank Dr SI Miranda, urologist at St Franciscus Gasthuis, and Dr $\dot{S}$ Gratama, pathologist, Bergwegziekenhis, Rotterdam, the Netherlands.

\section{References}

1. McCrea LE, Karafin L. Carcinoma of the prostate, metastases, therapy and survival. Journal of the International College of Surgeons 1958:29:723-8
2. Lenk S, Patzold D. Seltene Metastasen bei Prostatakarzinom Ein kasuistischer Beitrag. Zeitschrift fur Urologie und Nephrologie (Leipzig) 1973;66:293-5.

3. Abeshouse BS, Abeshouse GA. Metastatic tumors of the penis: a review of the literature and a report of two cases. J Urol 1961;86:99-112.

4. Spreen SA. Keys RH Jr, Evans AT. Acute urinary retention secondary to metastatic prostatic carcinoma to the penis: a case report. J Urol 1975;113:59.

5. Venable DD, Hastings D, Misra RP. Unusual metastatic patterns of prostate adenocarcinoma. J Urol 1983;130:980-5. 